Fanum

Sociológico

\section{Forum Sociológico}

Série II

$21 \mid 2011$

Transformação urbana

\title{
Em defesa da comunidade local e da consolidação da democracia numa cidade em processo de globalização: um exemplo de Boston
}

\author{
Tim Sieber et Maria Centeio
}

\section{(2) OpenEdition \\ Journals}

Édition électronique

URL : https://journals.openedition.org/sociologico/707

DOI : 10.4000/sociologico.707

ISSN : 2182-7427

Éditeur

CICS.NOVA - Centro Interdisciplinar de Ciências Sociais da Universidade Nova de Lisboa

Édition imprimée

Date de publication : 1 décembre 2011

Pagination : 13-22

ISSN : 0872-8380

\section{Référence électronique}

Tim Sieber et Maria Centeio, «Em defesa da comunidade local e da consolidação da democracia numa cidade em processo de globalização: um exemplo de Boston », Forum Sociológico [En ligne], 21 | 2011, mis en ligne le 27 février 2013, consulté le 31 mars 2022. URL : http://journals.openedition.org/ sociologico/707; DOI : https://doi.org/10.4000/sociologico.707

Ce document a été généré automatiquement le 31 mars 2022.

(c) CICS.NOVA 


\title{
Em defesa da comunidade local e da consolidação da democracia numa cidade em processo de globalização: um exemplo de Boston ${ }^{1}$
}

\author{
Tim Sieber et Maria Centeio
}

\section{Introdução: Boston como uma cidade em processo de globalização}

Durante a era de globalização e de crescente integração económica aos níveis nacional, regional e global que presentemente atravessamos a cidade americana de Boston viu a sua economia ser cada vez mais absorvida por redes globais mais alargadas, uma vez que as suas elites locais privilegiam este destino tentando tornar Boston o que eles chamam uma cidade "de nível mundial" atractiva ao investimento estrangeiro. Com efeito, Boston tem vindo a transformar-se numa versão em pequena escala do que Saskia Sassen há muito referiu como a "cidade global". De facto, em 2008, a revista Foreign Policy classificou Boston como a 29. entre as 60 mais importantes cidades globais a nível mundial, tomando como base a avaliação do seu comércio internacional, a qualidade da formação e do investimento no capital humano, a importância da cidade como centro de troca de informações, a sua oferta de actividades culturais e o seu grande envolvimento político a nível nacional e global. Numa dimensão, educação e formação da força de trabalho local, a cidade foi classificada como a número sete no mundo (Kearney, 2008). Possui um grande número de profissionais e gestores altamente treinados, muitos possuindo elevados graus académicos e, nos EUA, é a cidade com o maior número desses trabalhadores qualificados. Na força de trabalho de Boston, $58 \%$ da totalidade dos trabalhadores pertence a indústrias baseadas no conhecimento, o dobro da média total dos EUA (Frug e Barron, 2007). 
2 O investimento estrangeiro e a propriedade privada entraram em muitos sectoreschave da economia, tais como a biotecnologia, as indústrias transformadoras, as tecnologias de informação e software, as actividades ligadas ao imobiliário, as pescas e, como não podia deixar de ser, o comércio de importação-exportação. Por exemplo, as subsidiárias de empresas de capital estrangeiro na zona de Boston dão agora emprego a cerca de 200000 trabalhadores e controlam 11\% de todos os postos de trabalho na indústria transformadora (Smith, 2010). No sector financeiro, a integração é ainda maior, com quase um terço de todos os depósitos bancários na posse de estrangeiros e sendo três dos quatro maiores bancos da cidade estrangeiros, sediados em Espanha, no Reino Unido e no Canadá, com interesses bancários britânicos e franceses por parte de grandes investidores nos negócios locais e no sector do imobiliário (Kerber, 2008).

Inserindo-se num padrão comum no Norte Global, a globalização de Boston, durante os anos de 1990 a 2000, gerou um dramático aumento na gentrificação, à medida que cada vez mais profissionais e gestores trabalhando nos florescentes sectores financeiros e dos negócios escolhem essa cidade para local de residência, impulsionando os valores da propriedade e as rendas e fazendo deslocar muitas pessoas pobres e da classe trabalhadora para subúrbios afastados. Estas tendências têm vindo, de facto, a acentuar-se nos últimos 50 anos, à medida que a cidade se desindustrializou, perdeu a sua base, que assentava na indústria transformadora, e a sua economia se voltou cada vez mais para os serviços às empresas, a medicina, a alta tecnologia, as finanças e o imobiliário (Bluestone e Stevenson, 2002; Sieber, 2001). Estas deslocações na economia urbana levaram também à perda do controlo local sobre uma grande parte do espaço público, durante o processo que Saskia Sassen designou como deslocalização (Sassen, 1996: 210).

4 Só nos últimos 15 anos, 80000 habitações a preços aceitáveis e acessíveis à maior parte dos residentes desapareceram devido à crescente passagem de habitações para as mãos de privados. Falando da crise na acessibilidade à habitação em Boston, o Center for Urban and Regional Policy (Centro para a Política Urbana e Regional), na Northeastern University (Universidade do Nordeste), fez notar que "enfrentamos o equivalente a um desastre natural, tal como um furacão destruidor ou umas cheias" (Bluestone et al., 2001: i). A Boston Tenants Coalition (Coligação dos Inquilinos de Boston) comentou que desde há uma década que, em Boston, para se pagar a renda média pedida para um apartamento com duas divisões, $\$ 1400$ por mês, um agregado familiar precisaria de ganhar \$62 000 por ano; no entanto, dois terços dos agregados familiares de Boston ganhavam menos de $\$ 40000$ por ano. Não é de admirar que a Coligação de Inquilinos tenha concluído que "Boston está a perder a capacidade de alojar famílias trabalhadoras e pessoas com baixos rendimentos" (Boston Tenant Coalition, 2000: 13). Presentemente a situação é ainda mais grave e a cidade está ainda mais gentrificada.

Outra das importantes tendências que se deve ter em conta prende-se com o fluxo cada vez maior de novos imigrantes na cidade ao longo dos últimos 20 anos. Boston foi a última das maiores cidades dos EUA a tornar-se uma cidade com maioria de minorias, ou seja, com os brancos a constituir uma população minoritária. Boston há muito que é a capital e a metrópole dos seis estados da região de Nova Inglaterra, uma das regiões mais homogeneamente branca da nação, com uma população em contracção e envelhecida. Novamente em consonância com um padrão comum no Norte Global, incluindo várias zonas da Europa, o Estado de Massachusetts e Boston tornaram-se 
novamente o destino para um florescente tipo de novos imigrantes vindos de África, Ásia e da América Latina (Melnik, Dyer-Blake e Lima, 2009).

6 Presentemente, cerca de um terço da população são imigrantes, muitos deles ocupando postos de trabalho em serviços do nível mais baixo, que sustentam as classes média e alta em crescimento que estão a gentrificar a cidade. A desigualdade de rendimentos na área metropolitana de Boston e no estado do Massachusetts situa-se entre a mais dramática de todos os Estados Unidos (Sieber, 2001).

\section{O Dudley Street Corridor e a DSNI}

7 Certamente que todas estas tendências implicariam que um bairro no interior da cidade composto por pessoas de baixos rendimentos, sobretudo de minorias raciais e étnicas, e incluindo muitos imigrantes, muito dificilmente se sustentaria a si próprio, exerceria controlo sobre o seu próprio espaço urbano ou teria possibilidades de preservar habitação acessível e de qualidade a curta distância do centro financeiro desta cidade rica - no entanto, tal zona urbana existe de facto, sendo este o caso que aqui vamos estudar. Trata-se do Dudley Street Corridor, localizado nos bairros de Dorchester e Roxbury, em Boston, uma zona tradicionalmente pobre e de classes trabalhadoras, uma área que acolhe imigrantes desde há mais de 100 anos, cuja população é hoje em dia composta em $95 \%$ por minorias raciais. Este bairro tem sido capaz de se defender das especulações imobiliárias e da gentrificação e de melhorar a qualidade de vida, em todas as frentes, dos seus 23000 residentes das mais diversas raças e, na maior parte, de baixos rendimentos. 0 segredo deste sucesso assenta na notável organização do bairro, agora com 25 anos, que fez com que os residentes locais ganhassem controlo sobre o planeamento e sobre o espaço do seu próprio bairro. Esta organização chama-se Dudley Street Neighborhood Initiative, normalmente denominada pelo seu acrónimo, DSNI.

8 A DSNI foi formada há 25 anos por uma coligação de residentes e de prestadores de serviços locais para a defesa e revitalização de um dos bairros mais degradados de Boston, que tinha ficado sujeito ao abandono, a práticas discriminatórias, a negligência e fogo posto durante os anos 70 e o início dos anos 80. Em 1984, um total de 1300 lotes de terreno - cerca de metade do total - tinham sido reduzidos a pedras, a terrenos vazios, muitos deles transformados em locais de depósito ilegal de lixo tóxico a céu aberto. Através do desenvolvimento de uma abordagem abrangente que sustentasse a revitalização do bairro e dando particular atenção a intervenções ao nível físico, ambiental, económico e social, a DSNI conduziu um extraordinário plano de reconversão da zona. Tornou-se o primeiro bairro dos Estados Unidos, controlado por uma organização, a obter o direito de expropriação de terrenos abandonados e a coordenar o planeamento de reconstrução de centenas de novos lotes para habitação a preços acessíveis, para parques comunitários e espaços verdes e para dezenas de novos pequenos negócios detidos pelas minorias (ver Medoff e Sklar, 2003, para uma história inicial dos êxitos da DSNI).

\section{Métodos de pesquisa e exemplo de entrevista}

9 A DSNI foi objecto de estudo enquanto parte de um projecto mais alargado que investiga a integração dos imigrantes nas comunidades urbanas do Massachusetts. A pesquisa do autor teve lugar durante 2008-2009 e pretendeu explicar o modelo de 
organização da DSNI como sendo um conjunto de "boas práticas" para a construção de uma comunidade em bairros urbanos dos Estados Unidos, cada vez mais diferenciados e com uma intensa ocupação de imigrantes. A DSNI foi um colaborador activo na pesquisa, sendo que uma das investigadoras, Maria Centeio, era na altura membro do conselho da juventude e residente na área. Durante Julho e Agosto de 2008, foram conduzidas pelos autores vinte e sete entrevistas, com a duração de uma a três horas, a indivíduos indicados pelos responsáveis da DSNI como sendo conhecedores e actores importantes da história e desenvolvimento da "Initiative" em Boston. Dos vinte e sete indivíduos entrevistados, seis eram funcionários actuais (incluindo três que também eram residentes na comunidade) e outros dezoito eram residentes no bairro, incluindo membros da direcção, membros do comité e outros que, no passado, tinham exercido funções nas actividades da DSNI. O actual director executivo, John Barros, foi entrevistado, tal como o anterior director executivo, Gus Newport (Berkeley, Califórnia), e o fundador e anterior presidente da direcção, Nelson Merced (Washington, D. C.). Três dos entrevistados eram líderes religiosos residentes na comunidade que estiveram envolvidos na DSNI e na organização do bairro, o Rev. Paul Bothwell, um pastor da Igreja Baptista, o Padre Walter Waldron, pastor da Igreja de St. Patrick, e a Irmã Margaret Leonard, das Little Sisters of the Assumption (Irmãzinhas da Assunção) e directora executiva do Project Hope (Projecto Esperança), uma organização-chave fundada na comunidade que apoia as mulheres de baixos rendimentos e as sem-abrigo do bairro. Ao todo, a distribuição étnica dos entrevistados foi: afro-americanos, 22 por cento; cabo-verdianos, 37 por cento; latinos, 11 por cento; brancos, 22 por cento; e, outros, 8 por cento. Dez eram do sexo masculino e 17 do sexo feminino. Os entrevistados tinham idades entre os 15 e os 85 anos. A pesquisa incluiu também a participação activa nas actividades comunitárias da DSNI durante 2008, assim como o estudo de material documental da organização e da literatura publicada sobre as suas realizações, particularmente as relacionadas com as áreas dos estudos urbanos, organização comunitária e o trabalho social. 0 resultado aqui apresentado inspira-se, portanto, não só nesta mistura de trabalho etnográfico em primeira mão, como também em fontes de arquivo e fontes secundárias.

\section{Resistência à globalização e conservação do controlo local}

Dois pilares fundamentais da organização e do planeamento estratégico da DSNI são a chave que explica o seu sucesso na conservação do controlo local sobre o espaço urbano e na resistência face às pressões da globalização, mais do que em quaisquer outros bairros e zonas urbanas de Boston. O primeiro destes dois pilares prende-se com a criação de um fundo de terrenos comunitário que detém e gere os terrenos do bairro, e o segundo deve-se ao facto de ser um modelo de organização de comunidade que funciona para construir colaboração e comunhão que liguem as grandes diferenças culturais e linguísticas; disto resultou a unidade e a capacitação dos residentes, especialmente através da afirmação do controlo do bairro face às forças externas que o afectam.

11 1. O fundo de terrenos da comunidade: Dudley Neighbors, Inc. Entre 1985 e 1990, com quase metade das propriedades do bairro abandonadas pelos seus proprietários e a maior parte destas parcelas de terreno contendo casas incendiadas ou destruídas, ou tendo-se 
transformado em locais de depósito ilegal de lixo tóxico, a DSNI procurou com sucesso a obtenção de direitos para expropriar a maior parte destes terrenos abandonados, num total de cerca de 13 hectares. Uma vez obtido o controlo dos terrenos por parte da DNSI, esta cedeu-os a um fundo de terrenos comunitário sem fins lucrativos (Dudley Neighbors) que os conserva, controlando-os através de um conselho de direcção cujos membros foram eleitos de entre os residentes locais.

Existem mais de 200 fundos de terrenos comunitários nos Estados Unidos, em 44 estados e no Município de Columbia, que muitas vezes entraram na posse de substanciais áreas de terrenos através da compra, de ofertas ou expropriação. Os fundos de terrenos são organizações controladas por residentes locais, sem fins lucrativos e com isenção fiscal, que são constituídos para preservar terrenos para parques, zonas selvagens, terrenos tribais para os grupos indígenas, terrenos agrícolas e, por vezes, terrenos urbanos isolando-os das pressões do mercado, identificando-os como reserva comum e colocando-os sob o controlo democrático local (Peterson, 1996; Davis, 2010). Tudo isto evita que as forças do mercado inflacionem o seu valor e os transformem em recursos que possam entrar na posse de estranhos, particularmente de especuladores imobiliários. A deslocalização do controlo do espaço urbano que nos é familiar, que Saskia Sassen (1996) observa como sendo característica das cidades em processo de globalização, aqui simplesmente não acontece. Nos EUA, os exemplos dos fundos de terrenos comunitários são semelhantes aos bancos agrícolas europeus, têm as suas raízes históricas nos fundos de terrenos de Gandhi na Índia e foram introduzidos na América do Norte como ferramenta organizadora do Movimento Afro-Americano para os Direitos Civis.

13 Num cenário urbano como a Rua Dudley, os fundos de terrenos são uma forma de a população local ganhar o controlo democrático dos terrenos do seu próprio bairro para bloquear a especulação externa e para proteger a acessibilidade de preço de qualquer habitação que aí seja construída. Quando são construídas habitações nos terrenos, os proprietários compram apenas o edifício, não o terreno em si, e devem concordar em revendê-lo de acordo com as disposições que asseguram a acessibilidade de preço. $\mathrm{Na}$ zona da Rua Dudley, mais de 400 unidades habitacionais foram construídas nos terrenos cujo proprietário é o fundo. Durante a recente contracção económica, quando os valores das hipotecas para a habitação em Boston subiram precipitadamente, especialmente nas áreas de rendimentos mais baixos, como por exemplo Roxbury, nenhuma hipoteca de casa construída em propriedade do fundo de terrenos foi executada apesar de a taxa ser de $15 \%$ ou superior noutras zonas vizinhas (Sklar, 2009). Através do controlo da especulação e dos empréstimos predatórios nesta zona, o fundo de terrenos promove o controlo e a estabilidade do bairro e a coesão social entre os vizinhos.

14 2. O Modelo Organizacional da DSNI: Controlo de Residentes e Integração da Diversidade. Seguidamente, é importante referir o modelo organizacional da DSNI e, especialmente, a forma como conseguiu trazer unidade para o bairro, embora este seja bastante diversificado em termos étnicos, linguísticos e raciais. A sua estratégia organizativa conseguiu transformar potenciais barreiras culturais em pontes e produziu uma enorme força de apoio popular no bairro, tendo ganho o respeito do governo, de fundações, de grupos académicos e do sector empresarial privado. O princípio fundamental da estratégia organizacional da DSNI é garantir uma governação residente forte e o controlo da organização e dos seus projectos para o bairro. Num bairro urbano 
tão heterogéneo e com acentuadas diferenças culturais, como o de Dudley, estas condições poderiam parecer colocar um desafio difícil, mas, como iremos ver, para a DSNI constituiu um desafio bem-sucedido.

Uma iniciativa pouco usual baseada no lugar: que inclui todos os que aí vivem e trabalham. Na sua génese, os princípios da DSNI emanaram de uma iniciativa baseada no lugar e o seu compromisso fundamental formou-se a partir da participação democrática. Os limites da DSNI são definidos em termos de proximidade geográfica e o princípio primordial que lhe está associado é que todas as pessoas aí residentes - literalmente "todas as pessoas" - são membros da DSNI, reais ou potenciais. O controlo do residente em termos de governação, as votações, a representatividade e as tomadas de decisão são cruciais. $\mathrm{O}$ conselho directivo da Initiative, ao contrário do que acontece na maioria das organizações sem fins lucrativos, está limitado a pessoas que vivem ou trabalham no bairro. Os funcionários não têm de ali viver, embora isso aconteça com a maioria, e não lhes é permitido votar as decisões a não ser que também sejam residentes. A definição do seu âmbito geográfico, tal como o faz, obriga a DSNI a ser inclusiva em relação a todos os tipos de pessoas neste bairro onde tão profundamente se misturam cor, religião, etnia e classe.

Controlo do Residente. $\mathrm{O}$ foco nos "residentes" e o seu direito a terem uma palavra a dizer quanto ao desenvolvimento do seu bairro sempre foi uma das intenções da estratégia organizacional da DSNI. Tal como explicou o afro-americano Renay Peters, membro da direcção do fundo de terrenos comunitário Dudley Neighbors: "As pessoas que constituem a direcção vivem na comunidade. Como é que se pode falar do assunto se não se vive lá? Têm mais orgulho nela, estão mais preocupadas com ela e realizam mais coisas."

Como disse May Louie, funcionária há muito tempo, sobre o seu trabalho de formação junto do Resident Development Institute (Instituto para o Desenvolvimento do Residente), o princípio do controlo pelos residentes significa "procurar o compromisso de quem está envolvido e a residir no bairro no diálogo directo sobre o que está a acontecer. Eu preservo o conceito de que os residentes estão primeiro. Eu transporto isso para onde quer que vá: que outro modo haverá para se conseguir sentar à mesa as vozes autênticas?"

18 Nunca foram feitas distinções entre as gentes locais com base no estatuto de cidadania ou imigração, mesmo tendo em conta que o bairro foi tradicionalmente receptor de imigrantes, presentemente estimando-se em $41 \%$, sempre com uma mistura de estatutos, incluindo pessoas sem documentação. Intencionalmente e a fim de unir o bairro, a organização nunca usou a retórica da "cidadania" ou da "acção do cidadão" para descrever a sua base de apoio popular. Foi escolhido o "controlo do residente" por ser um conceito mais inclusivo. Em contraste com as agências ou organizações directamente ligadas ao estado, existe uma notável falta de atenção nas actividades da DSNI relativamente ao estatuto dos imigrantes: ser cidadão dos EUA, residente condicional ou permanente, ou ser portador ou não de documentação é perfeitamente irrelevante para definir o seu sentido de pertença à comunidade. Tal como referiu Joceline Fidalgo, uma jovem participante de 15 anos: "Aqui, eles não tratam os imigrantes e os não-imigrantes de maneira diferente, talvez por o bairro ser constituído por muitos imigrantes." É o lugar, portanto, e não o estatuto de cidadania ou de grupo étnico, que define o direito das pessoas a terem uma voz quanto à forma como a sua própria comunidade é planeada e desenvolvida. 

valorizado através da forte ênfase dada à liderança popular de base alargada dentro da comunidade e pela convicção de que todas as pessoas podem aprender competências e capacidades necessárias ao exercício da liderança, colaborando com os vizinhos e facilitando os esforços conducentes à concretização bem-sucedida dos objectivos, mesmo que elas não tenham sido previamente identificadas como líderes. Como observou May Louie, "As pessoas nas comunidades urbanas pobres têm realmente uma profunda sabedoria. Os residentes e outros intervenientes podem compreender quais as necessidades do seu bairro e isso pode funcionar muito melhor do que se tivermos simplesmente em conta aquilo que os especialistas sabem." Juntamente com a autoridade largamente partilhada sobre todos os assuntos que dizem respeito ao bairro, ela também referiu: "Nós abordámos a questão da construção da comunidade como sendo um projecto para todos." Tal como explicou o anterior presidente da direcção, Che Madyun, esta é uma forma de "construir o potencial da comunidade". A DSNI organiza regularmente workshops integrados no seu Resident Development Institute (Instituto para o Desenvolvimento do Residente), que oferece formação em liderança e técnicas de organização para todos os que estão envolvidos activamente em comités, equipas de decisão e grupos de planeamento.

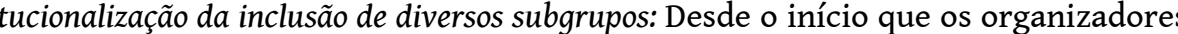
da DSNI pretenderam fazer reflectir a diversidade do bairro na sua própria infraestrutura institucional, consagrando permanentemente várias medidas que enfatizassem a inclusão. $O$ seu conselho de direcção, composto por 34 membros eleitos, está estruturado de forma a proporcionar uma representatividade o mais alargada possível da mistura étnica do bairro, sendo que $60 \%$ dos lugares estão afectos a residentes. Os 23000 residentes que aí vivem são 38\% afro-americanos, $29 \%$ latinos, 25\% cabo-verdianos e $7 \%$ brancos, frequentemente famílias americanas, incluindo muitos idosos.

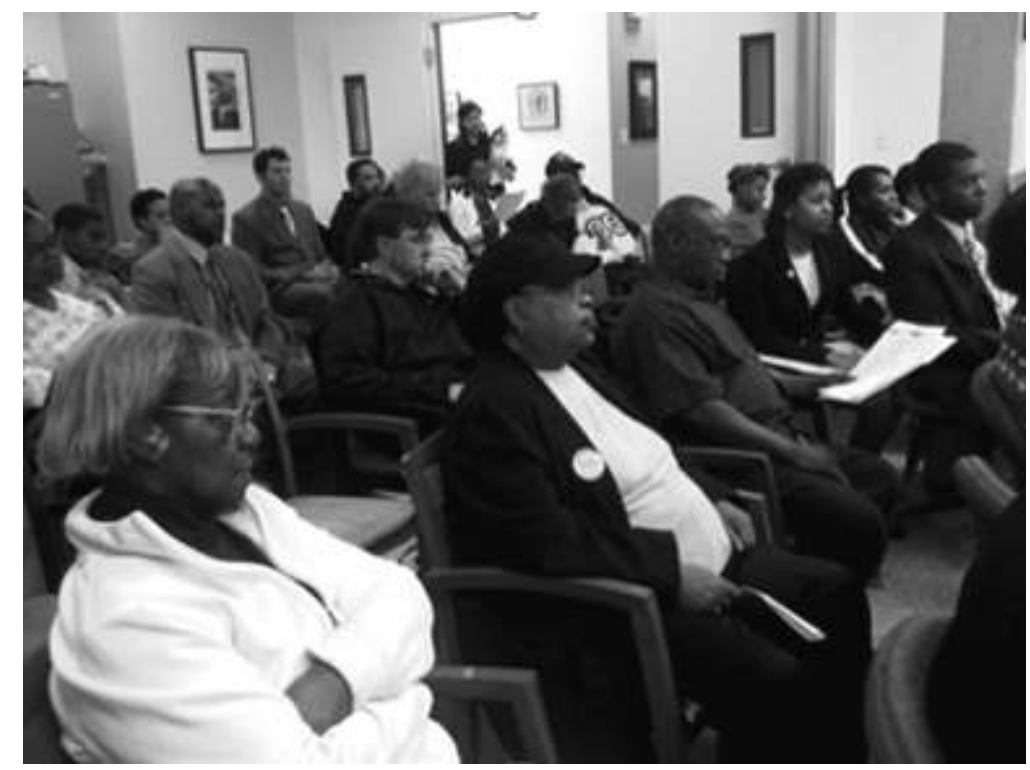

Reunião Comunitária da DSNI (Foto: Robert Haas)

21 Paridade de Poder entre Grupos Étnicos. A composição do conselho de direcção da DSNI exige uma representação igual dos principais grupos étnicos do bairro, incluindo quatro lugares para os afro-americanos, quatro para os latinos, quarto para os cabo-verdianos, 
quatro para os brancos e três para jovens com idades compreendidas entre os 15 e os 17 anos, que são normalmente também uma mistura de etnias. A DSNI tem evitado a distribuição do poder e da autoridade na organização baseada em qualquer cálculo relacionado com a regra da maioria ou da proporcionalidade numérica, assegurando que todos os segmentos étnicos da comunidade, mesmo se minorias em números comparativos, sejam igualmente representados. Ninguém poderá sentir que eles estão incluídos como símbolos ou minorias, e não como iguais. Como referiu Jason Webb, o actual Director de Operações de Pessoal, este plano foi "muito engenhoso" pois permitiu à comunidade evitar "ficar-se pela raça... queremos ter a certeza de que todos têm um lugar igual à mesa... não é o mesmo que a regra da maioria". 0 organizador, José Barros, disse que este sistema assegura que "cada grupo étnico tem a possibilidade de estar ao mesmo nível e de ter os seus próprios líderes na comunidade... existe a oportunidade para que todos os grupos se tornem líderes a todos os níveis".

Os restantes lugares do conselho de direcção destinam-se a indivíduos de outros grupos intervenientes do bairro: organizações sem fins lucrativos, sobretudo prestadores de serviços (7), proprietários de pequenos negócios (2), organizações religiosas (2), empresas de desenvolvimento comunitário (2), e residentes nomeados pelo conselho (2). Assim, o conselho de direcção da DSNI constitui, de facto, uma coligação de intervenientes no bairro, de diversas circunscrições, cuja missão fundamental é a de promover o diálogo e a colaboração entre estes vários intervenientes, incluindo os que representam diferentes grupos étnicos. Isto torna o projecto de trabalhar novos limites culturais e diferentes interesses e de encontrar um terreno comum a tarefa organizativa fundamental do conselho, obviamente essencial à criação da coligação eficaz que tão bem planeou e defendeu o bairro.

Um bairro que comunica em várias línguas. Outro pilar-chave do sucesso da DSNI na construção da comunidade foi a sua decisão de funcionar como uma organização multilingue. o compromisso com o multilinguismo reflecte simplesmente o que é audível nas ruas e lojas locais e na principal paróquia católica do bairro, St. Patrick, que celebra missas todos os domingos em cada uma das três línguas reconhecidas pela própria DSNI - inglês, crioulo cabo-verdiano e espanhol. Na DSNI a maioria dos assuntos oficiais e a comunicação fazem-se em três línguas. Em todas as reuniões formais que envolvam público é disponibilizada tradução simultânea com auscultadores. Nos escritórios da DSNI, pode ouvir-se falar todas as três línguas ao longo do dia, em conversas presenciais e nas que ocorrem ao telefone. Visto que as reuniões, a publicidade, os eventos e acontecimentos sociais e todas as publicações da DSNI são multilingues, o funcionamento da organização e os diálogos que ela promove ao nível da comunidade são acessíveis a toda a gente.

Os primeiros organizadores empenharam-se em demonstrar as razões para este compromisso inicial com o multilinguismo. O primeiro presidente do conselho de direcção, Nelson Merced, fez notar que seria uma necessidade assegurar uma participação democrática alargada por parte dos residentes do bairro: "Tornou-se para nós bastante óbvio que vivíamos num bairro multiétnico e multi-racial e, na primeira reunião [em 1984] tivemos intérpretes. Queríamos que todos compreendessem o que estávamos a discutir e o que estávamos a acordar. Queríamos que todos compreendessem o que decidíamos e porque o decidíamos. Queríamos que todos os presentes pudessem expressar-se e emitir as suas opiniões. Para que as pessoas possam realmente dizer aquilo que pensam, têm de o fazer no seu próprio idioma." 

que as diferenças linguísticas podiam apresentar um desafio. Se existir vontade de trabalhar com elas, o multilinguismo pode, portanto, proporcionar pontes para a participação, em vez de criar barreiras, e pode promover uma melhor identificação e receptividade relativamente às necessidades da comunidade.

portante notar que a solução dos problemas resultantes de uma potencial desunião, de um conflito e da falta de comunicação que podem surgir das diferenças raciais, étnicas e linguísticas não passa somente pela criação de uma atmosfera mais feliz e mais harmoniosa entre os participantes para seu benefício. Em vez disso, a solidariedade foi essencial para o bairro conseguir desenvolver, mostrar e defender a sua unidade para com os elementos vindos do exterior. Os residentes tiveram uma longa e histórica experiência de serem "divididos e governados", de integrarem pessoas de fora e de a cidade ter colocado um bairro contra outro. Além do mais, activistas de todas as convicções foram muitas vezes acusados - por aqueles que detinham o poder e os recursos para dar, quer públicos quer privados - de não serem "representativos da comunidade". Tal como disse Paul Bothwell, membro do conselho de direcção há muito tempo: "Um dos nossos valores está na voz colectiva e no poder do bairro, e isso significa toda a gente - grupos etários, culturais e linguísticos e todo o tipo de interveniente. Você vive aqui, você trabalha aqui. Se não estivermos todos juntos, o dividir para reinar, de facto, funciona."

Construindo a Aldeia, uma comunidade que se preocupa. O objectivo da DSNI foi, desde o início, construir na sua zona urbana devastada o que os primeiros líderes chamaram uma "aldeia urbana", uma comunidade que fosse segura, saudável, que apoiasse as famílias e os indivíduos, espiritualmente sã, com esperança e sustentável tanto a nível económico como ambiental, para além de ser politicamente empenhada naquilo que lhe trouxesse benefícios. O seu modelo de desenvolvimento também promovia o desenvolvimento económico local sustentável, em que se incluía: a criação de pequenos negócios; exigências às autoridades públicas tendentes a melhorar os serviços prestados aos residentes em termos de cuidados de saúde, educação, actividades de lazer, parques e saneamento; e estruturas adequadas à participação da comunidade no planeamento de decisões que afectassem o seu bem-estar. A introdução da visão da "aldeia" sonhada sempre foi uma preocupação humanitária e ética, e um acto de amizade de uns residentes com outros. De facto, muitos residentes estão convencidos que Dudley é um bairro único em termos de calor humano e amizade resultantes destes valores éticos.

Muitos acreditam que o sentido de posse e de orgulho no bairro que a DSNI promove, por exemplo, resulta numa vida de rua que é mais amigável e facilitada do que noutros lugares. Muitos na DSNI, tais como May Louie, descrevem-na como a "pulsação do bairro". Tal como frisou um anterior organizador, "Agora a maioria das pessoas já se conhece e fala entre si. E parece ser mais uma família do que um bairro". 0 anterior presidente do conselho de direcção, Julio Henriquez, diz que o bairro lhe lembra a pequena cidade no Panamá onde cresceu. Putnam e Feldstein relatam a conversa que tiveram com ele sobre este assunto:

Ambas são pequenas comunidades só com uma igreja paroquial, onde as pessoas conhecem os seus vizinhos. Uma rapariga avança para Henriquez. "Boa tarde", diz ele. Ela estabelece contacto visual, sorri e diz-lhe olá. "Quando eu mudei para este bairro", diz Henriquez, "todos se comportavam como estranhos. Ninguém dizia bom dia a ninguém" (Putnam e Feldstein, 2003: 89). 
Outra das dimensões importantes da formação da comunidade pela DSNI está evidenciada na organização das áreas levada a cabo pela equipa de funcionários - lotes de terreno vazios - onde agora estão a ser construídas novas habitações para compradores referenciados. Um ano antes de as habitações estarem concluídas e prontas a ocupar, os compradores são normalmente seleccionados por sorteio e, uma vez identificados, iniciam contactos informais, procuram saber das respectivas histórias de vida e planeiam os pormenores do bloco que irão ocupar, inclusivamente das zonas verdes. Isto foi relatado por Diane Dujon, residente no bairro e compradora de uma habitação:

Eles fizeram com que os vizinhos se conhecessem mesmo antes de se mudarem para lá. Eles promoveram reuniões e tivemos oportunidade de conhecer as respectivas famílias antes de nos mudarmos. Em dez anos, só uma família saiu do bairro! Sentimo-nos ligados. Eles fizeram com que nos sentíssemos verdadeiros vizinhos. Cuidamos uns dos outros. Preocupamo-nos uns com os outros. Na porta ao lado moram hispânicos, do outro lado da rua, haitianos e, do outro lado, afroamericanos. Somos vizinhos, partilhamos diferentes experiências e conseguimos conhecer-nos uns aos outros. Aqui, pode sentir-se o sentimento da comunidade.

Usando a Arte para Construir a Comunidade. Finalmente, é importante reconhecer que a DSNI utiliza a cultura de uma forma muito eficaz para criar uma comunhão através das diferenças e para construir uma unidade. Por exemplo, muitos dos murais existentes no bairro, grande parte concebidos e executados com a participação dos jovens locais, evidenciam e chamam a atenção dos residentes para a história do bairro, elogiam a riqueza das suas diferentes heranças culturais e desafiam os residentes a trabalhar em prol da paz e harmonia entre os diferentes grupos. Tal como Jason Webb refere:

Para os residentes, os murais são poderosos símbolos da comunidade. Eles projectam as mensagens do nosso passado e antecipam o futuro. Os jovens orgulham-se de os conceber, de os executar e sentem-nos como propriedade sua. Os nossos murais não têm graffiti há 30 anos! Noutros locais, os murais da C.D.C. ${ }^{2}$ dinamizados pela equipa de funcionários com reduzida participação da comunidade são grafitados na primeira semana e, quando isso se observa, podemos estar certos de que não houve envolvimento da comunidade.

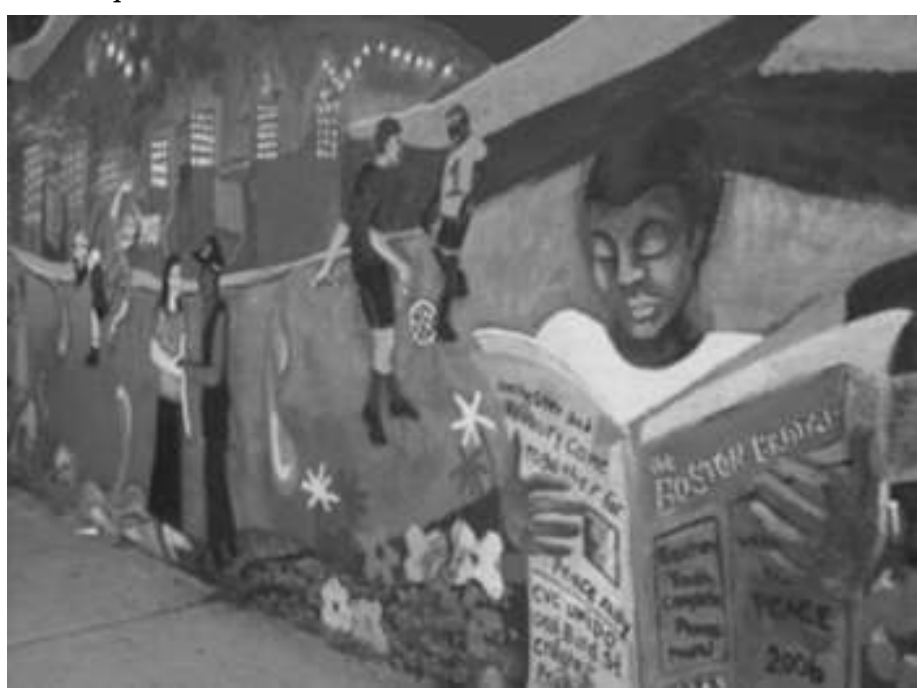

O mural "Rua Dudley Peace” celebrando a harmonia inter-étnica (Foto: Tim Sieber)

31 Outros tipos de arte são também usados para celebrar a unidade na diferença e o poder do bairro. Na reunião anual de 2008 da DSNI, Alicia Mooltrey, uma afro-americana de 22 
anos e funcionária coordenadora do programa de empregos de Verão para jovens, leu às centenas de pessoas aí presentes um poema que ela escrevera, intitulado "Quem são estas pessoas?". O seu poema reconhecia abertamente a beleza e a força da adesão multi-racial à DSNI e a sua determinação em exercer o poder no seu bairro.

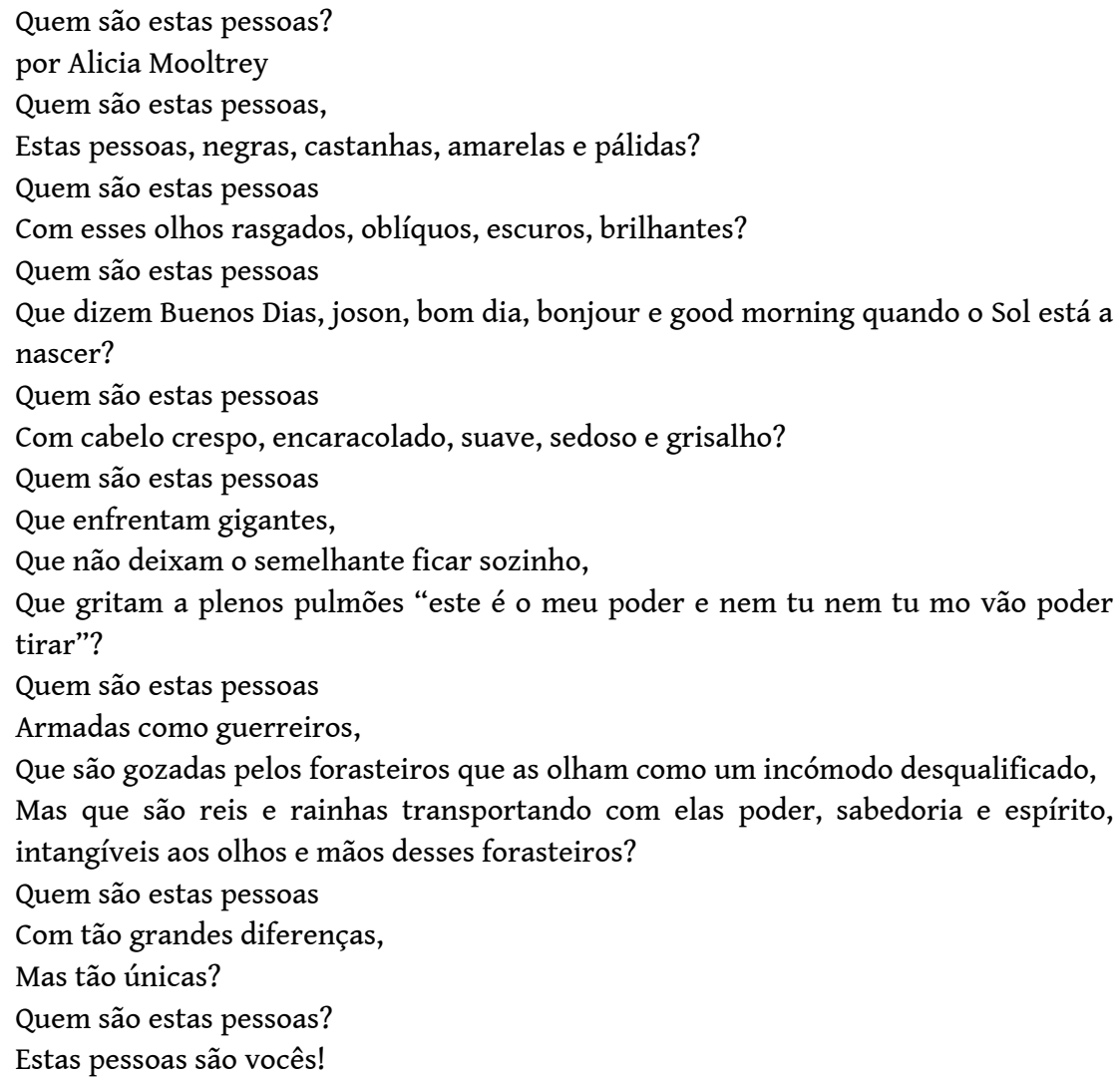

\section{Discussão e conclusões: o compromisso com a democracia}

O tipo de construção comunitária produzido pelo modelo da DSNI no bairro de Roxbury-Dorchester em Boston funciona como um cadinho eficaz para o exercício da democracia urbana de raiz popular. Mark Purcell, entre muitos outros observadores do actual cenário urbano, reportou de forma convincente o aparente "declínio da democracia... nas cidades", especialmente a "crescente privação de direitos civis dos habitantes urbanos" que está a acontecer a um nível global (2002: 100-101), particularmente no que respeita ao controlo do espaço público.

Na DSNI, os activistas chamam ao programa de participação democrática da Initiative "democracia plena", nas palavras de May Louie, ou "actualização da democracia quarteirão a quarteirão", como o Director Executivo John Barros o denomina (Putnam e Feldstein, 2003: 97). O exemplo da DSNI pode ser surpreendente no contexto norteamericano, mas simplesmente porque as avaliações convencionais das políticas urbanas de base popular tinham ignorado esse tipo de iniciativa democrática que, efectivamente, está a aparecer cada vez mais por todo o mundo urbano a nível global. Como o antropólogo Arjun Appadurai explicou, as tendências que vão no sentido da privação de direitos civis nas áreas urbanas são o resultado da globalização, que estabeleceu um padrão "no qual as «cidades-mundiais» mais ricas cada vez mais 
frequentemente funcionam como cidades-estado numa economia global em rede, cada vez mais independente da mediação regional e nacional, e onde as cidades mais pobres - e as populações mais pobres aí existentes - procuram novas formas de reclamar espaço e voz" (Appadurai, 2002: 24).

Contudo, neste padrão global baseado nos seus estudos de organização entre os pobres em Bombaim, Appadurai vê um novo tipo de política com base popular a emergir, a que chama "democracia profunda", e que explica como sendo "uma nova forma de governabilidade urbana vinda de baixo", caracterizada pela inclusão, participação e transparência (Appadurai, 2002: 35). A democracia profunda é "fundamentalmente populista e antiespecializada em termos de estratégia e essência", com "métodos de organização, mobilização, ensino e aprendizagem assentes no que as pessoas pobres já conhecem e compreendem" (Appadurai, 2002: 20).

Este novo tipo de política urbana já suplantou em certos locais as noções tradicionais mais antigas de cidadania popular. Como escreve Appadurai, estes "movimentos entre os pobres urbanos... representam esforços tendentes à reconstituição da cidadania nas cidades" (2002: 24). Uma visão do que esta nova forma de cidadania pode vir a ser é articulada por Mark Purcell, inspirando-se nas ideias prescientes do sociólogo francês Henri Lefebvre, especialmente no seu trabalho seminal sobre $O$ Direito à Cidade (Lefebvre, 1968). Purcell observa que, conforme argumentou Lefebvre, o poder de criar e controlar a estruturação das relações sociais, políticas e económicas na cidade acentua os direitos dos "habitantes", muito à maneira do que acontece com os "residentes" da DSNI.

Presentemente, a concessão de direitos formais é largamente baseada na cidadania nacional. Aqueles que são cidadãos nacionais são elegíveis para participar em vários aspectos dos processos de decisão do estado. Na concepção de Lefebvre, contudo, a concessão de direitos aplica-se àqueles que habitam a cidade. No direito à cidade, a adesão à comunidade de pessoas com direitos civis não é um acidente de nacionalidade ou nascimento, mas antes um direito pelo facto de viverem as rotinas do dia-a-dia no espaço da cidade. $O$ povoamento urbano confronta directamente a cidadania nacional como a base dominante para a adesão política (Purcell, 2002: 102-103).

Mesmo que nem toda a gente possa votar e mesmo que algumas pessoas não tenham documentação, os residentes podem, ainda assim, empenhar-se na participação política - não somente a nível cívico mas até ao nível da política eleitoral, participando em reuniões, trabalhando nas campanhas, usando emblemas e fazendo contribuições monetárias (Leal, 2002). Entidades sem fins lucrativos, como a DSNI, ganham em credibilidade por representarem a totalidade do bairro, incluindo todas as pessoas desse mesmo bairro. Os organizadores explicaram que a inclusão, pela DSNI, de todos os grupos significou que as exigências da comunidade que eles preconizavam não poderiam nunca ser declaradas como sendo as posições de uma só facção étnica e que as autoridades não poderiam usar a estratégia do "dividir para reinar" contra eles. Pode ser que iniciativas e organizações com a DSNI partilhem algo de importante com os movimentos sociais: podem organizar enormes coligações de pessoas que lutem por um propósito comum, e ter mais força a nível político do que o estatuto social e a cidadania dos seus membros, individualmente, o poderia sugerir à partida.

38 A manutenção deste estado de constante mobilização facilita sem dúvida o sucesso continuado da DSNI, ao procurar empenhar os residentes da comunidade a participarem nos esforços da Initiative no desenvolvimento do bairro e na defesa e 
ampliação dos ganhos decorrentes da sua reabilitação. Noutras áreas de Boston, onde outras organizações têm uma forte história na organização da participação da comunidade, como por exemplo com o desenvolvimento da Villa Victoria no extremo Sul de Boston, Mario Luis Small detectou uma forte diminuição na participação da comunidade por parte de faixas etárias e gerações mais novas, as quais não tiveram uma sensibilização forte para a mobilização política contra a gentrificação e deslocação, como acontecera no início do projecto (Small, 2002, 2004). Além disso, a principal organização nesse bairro, Inquilos Boricuas en Acción (IBA), como refere, "é fundamentalmente uma organização prestadora de serviços sociais" (Small, 2002: 19). A DSNI, pelo contrário, adoptou uma estratégia deliberada para evitar a oferta de serviços, em vez disso define-se como uma organização de planeamento e de defesa. A sua missão principal é a organização dos residentes e não a prestação de serviços.

Outros dois factores são provavelmente também relevantes para o elevado nível de participação e envolvimento sustentados da comunidade na organização. Primeiro, a Initiative representa uma coligação de residentes, trabalhadores, empreendedores e prestadores de serviços dentro do próprio bairro e este tipo de "organização de construção comunitária" é particularmente bem-sucedida no que respeita a incentivar ao envolvimento cívico em áreas urbanas e na forma como promove ligações transversais que criam solidariedadade (Small, Jacobs e Massengill, 2008: 408-409). A necessidade de um diálogo cívico activo entre diversos parceiros é deste modo construído dentro da própria estrutura da Initiative. Segundo, a DSNI, ao chamar a si a governação da diversidade étnica e linguística, também promove o diálogo contínuo e a negociação entre os grupos participantes como necessidades solidárias básicas que devem ser activamente construídas e que não se pode assumir que existam, como acontece em bairros etnicamente mais homogéneos. Como argumentam Lamont e Small, em contraste com avaliações mais pessimistas do impacto da diversidade cultural na cultura cívica (por ex., Putnam, 2007), a presença e o desafio da diversidade pode constituir uma força positiva na promoção de intercâmbio, inovação e autoeficiência dentro da comunidade (Lamont e Small, 2010: 173-4).

O verdadeiro segredo do sucesso da DSNI é, portanto, o seu compromisso com a democracia - não só processual mas substantivo. Em relação à política eleitoral, mesmo que nem todos os que estejam envolvidos na DSNI tenham o direito de voto e outros direitos formais de cidadania, é certo que os políticos prestam particular atenção a esta organização; aparecem regularmente, falam nos eventos que esta realiza na comunidade e procuram activamente o seu apoio, porque respeitam e compreendem o poder da mobilização eficaz dos cidadãos. E, finalmente, a democracia local e a mobilização popular - se profundamente institucionalizadas ao nível local através de uma organização adequada - podem ter poderosos efeitos. Podem proporcionar às comunidades recursos e estruturas que lhes permitam controlar e defender o espaço do seu bairro da apropriação, fragmentação e alienação por parte de interesses e forças exteriores. Podem ajudar a comunidade a criar aliados no espectro político que possam reforçar esta protecção e o controlo local. Iniciativas como as da DSNI parecem estar também ao alcance de qualquer comunidade, embora, obviamente, as possibilidades que se lhes oferece variem de acordo com os diferentes contextos nacionais e locais e exijam sempre avaliações estratégicas e uma organização criativa para serem bemsucedidas. 


\section{BIBLIOGRAPHIE}

APPADURAI, A. (2002), “Deep Democracy: Urban Governmentality and the Horizon of Politics”, Public Culture, 14 (1), pp. 21-47.

BLUESTONE, B., C. C. Euchner e G. Weismann (2001), A New Paradigm for Housing in Greater Boston, Boston, Northeastern University Center for Urban \& Regional Policy.

BLUESTONE, B. e M. H. Stevenson (2002), The Boston Renaissance: Race, Space, and Economic Change in an American Metropolis, Nova Iorque, Russell Sage Foundation.

BOSTON TENANT COALITION (2000), Turning New Growth into Affordable Housing, Boston, Boston Tenant Coalition.

DAVIS, J. E. (2010), The Community Land Trust Reader, Cambridge, Lincoln Institute of Land Policy. DUDLEY STREET NEIGHBORHOOD INITIATIVE (2011), Dudley Neighborhood Profile. URL: http:// www.dsni.org/urban_village/DudleyProfilefinal.pdf, acedido a 31 de Janeiro de 2011.

FRUG, G. E. e D. J. Barron (2007), Boston Bound: A Comparison of Boston's Legal Powers with those of Six Other Major American Cities, Boston, The Boston Foundation.

KEARNEY, A. J. (2008), “The 2008 Global Cities Index”, Foreign Policy, 15 de Outubro, 2008.

KERBER, R. (2008), “Mass. Globalization”, The Boston Globe, 2 de Novembro, 2008.

LAMONT, M. e M. L. Small (2010), “Cultural diversity and anti-poverty policy”, International Social Science Journal, 61 (199), pp. 169-180.

LEAL, D. L. (2002), "Political participation by Latino Non-Citizens in the United States", British Journal of Political Science, 32 (2), pp. 353-370.

LEFEBVRE, H. (1968), Le Droit à la Ville, Paris, Anthropos.

MEDOFF, P. e H. Sklar (1993), Streets of Hope: The Fall and Rise of an Urban Neighborhood, Boston, South End Press.

MELNIK, M., N. Dyer-Blake e A. Lima (2009), New Bostonians 2009. Boston, Boston Redevelopment Authority and the Mayor's Office of New Bostonians.

PETERSON, T. (1996), “Community Land Trusts: an Introduction”, Planners Web: Planning Commissioners Journal, 23. URL: www.plannersweb.com, acedido a 1 de Novembro de 2010.

PUTNAM, R. D. e L. M. Feldstein (2003), Better Together: Restoring the American Community, Nova Iorque, Simon \& Schuster.

PURCELL, M. (2002), "Excavating Lefebvre: The right to the city and its urban politics of the inhabitant", GeoJournal, 58, pp. 99-108.

PUTNAM, R. D. (2007), "E Pluribus Unum: Diversity and Community in the Twenty-First Century", Scandinavian Political Studies, 30 (2), pp. 137-174.

SASSEN, S. (1996), "Whose City Is It? Globalization and the Formation of New Claims", Public Culture, 8 (2), pp. 205-223.

SIEBER, R. T. (2001), Boston 2001, a dynamic and ever changing city. www.symphonyofacity.org/ 01investigate/neighborhoods.html. 
SKLAR, H. (2009), “No Foreclosures Here”, Yes! Magazine, Inverno de 2009. URL: http:// www.yesmagazine.org/issues/sustainable-happiness/no-foreclosures-here, acedido a 1 de Maio de 2011.

SMALL, M. L. (2002), “Culture, Cohorts and Social Organization Theory: Understanding Local Participation in a Latino Housing Project”, American Journal of Sociology, 108 (1), pp. 1-54.

SMALL, M. L. (2004), Villa Victoria: The Transformation of Social Capital in a Boston Barrio, Chicago, University of Chicago Press.

SMALL, M., E. M. Jacobs e R. P. Massengill (2008), “Why Organizational Ties Matter for Neighborhood Effects: A Study of Resource Access through Childcare Centers”, Social Forces, 87 (1), pp. 387-414.

SMITH, J. F. (2010), “Globe 100 - Global Appeal”, The Boston Globe, 18 de Maio, 2010.

\section{NOTES}

1. Esta pesquisa foi financiada através de uma bolsa da Sociological Initiatives Foundation, sob administração do Trotter Institute para o Estudo da Cultura Negra na Universidadde de Massachusetts, Boston. $\mathrm{O}$ nosso agradecimento especial aos funcionários e à administração da Dudley Street Neighborhood Initiative, pela sua colaboração desinteressada nesta pesquisa e, particularmente, a Ros Everdell, May Louie, John Barros e José Barros.

2. A CDC (Community Development Corporation) é uma ONG que promove habitação para populações com baixos rendimentos.

\section{RÉSUMÉS}

Boston, Massachusetts, EUA, exibe, em escala reduzida, as principais particularidades de uma "cidade mundial", evidenciando os efeitos da globalização económica. As tendências incluem o crescente controlo económico estrangeiro, a crescente "deslocalização" do espaço da cidade, a gentrificação intensiva e novas vagas de imigrantes que engrossam os níveis mais baixos do sector terciário. Um bairro, o Dudley Street Corridor, resiste com sucesso à globalização a nível local, através da manutenção dos preços da propriedade imobiliária em níveis estáveis, mesmo aquando do colapso do mercado da habitação, da estabilidade social enquanto comunidade multiétnica e do controlo local do espaço urbano. O sucesso do bairro, em termos de autoprotecção, reflecte o trabalho da sua organização de planeamento local, a Dudley Street Neighborhood Initiative (DSNI), usando um fundo de terrenos comunitário e um modelo de organização de partilha de espaço que cria laços de solidariedade entre populações de diferentes etnias e promove a democracia local unindo todos os residentes. A "democracia profunda", nas palavras de Appadurai, e os habitantes urbanos reclamando o seu "direito à cidade", nas palavras de LeFebvre, são disso o resultado.

Boston, Massachusetts, USA, exhibits on a small scale cardinal features of a "world city," showing effects of economic globalization. Trends include growing foreign economic control, increasing "delocalization" of city space, intensive gentrification, and new immigrant waves filling lower 
rungs of a service economy. One neighborhood, the Dudley Street Corridor, successfully resists globalization at the local level, by maintaining stable real estate prices during housing market collapse, social stability as a multi-ethnic community, and local control of urban space. The neighborhood's success at self-defense reflects the work of its local planning organization, the Dudley Street Neighborhood Initiative (DSNI), using a community land trust, and a place-oriented organizing model that builds solidarity across ethnic lines and promotes local democracy uniting all residents. "Deep democracy", in Appadurai's terms, and urban inhabitants claiming their "right to the city", in LeFebvre's terms, are the result.

\section{INDEX}

Keywords : globalization, urban space, community organizing, land trust

Palavras-chave : globalização, espaço urbano, organização comunitária, fundo de terrenos

\section{AUTEURS}

\section{TIM SIEBER}

Departamento de Antropologia, Universidade do Massachusetts Boston (tim.sieber@umb.edu)

\section{MARIA CENTEIO}

Harvard College (mdcenteio@gmail.com) 